\title{
Clickable methyltetrazine-indocarbocyanine lipids: a multi-color toolkit for efficient modifications of cell membranes
}

Hanmant Gaikwad ${ }^{1,2}$, Guankui Wang1,2,3, Weston J. Smith ${ }^{1}$, Keisha L. Alexander ${ }^{4}$, Angelo D’Alessandro ${ }^{4}$, Wei Zhang ${ }^{5}$, Enkhtsetseg Purev ${ }^{5}$, Dmitri Simberg 1,2,3

${ }^{1}$ Translational Bio-Nanosciences Laboratory, ${ }^{2}$ Department of Pharmaceutical Sciences, The Skaggs School of Pharmacy and Pharmaceutical Sciences, University of Colorado Anschutz Medical Campus, Aurora, CO, 80045, USA

${ }^{3}$ Colorado Center for Nanomedicine and Nanosafety, University of Colorado Anschutz Medical Campus, Aurora, CO, 80045, USA

${ }^{4}$ Department of Biochemistry and Molecular Genetics, University of Colorado DenverAnschutz Medical Campus, Aurora, CO, 80045, USA

${ }^{5}$ Division of Hematology, School of Medicine, University of Colorado Anschutz Medical Campus, Aurora, CO, 80045, USA 


\section{1) Supplemental Methods:}

\section{Synthesis of DOCy7-methylamine}

Di-Octadecayl Cyanine 7 (DOCy7)-methylamine was synthesized by modification of previously reported Cyanine 7 synthesis. ${ }^{1,2,3}$ Synthesis of 2,3,3-trimethyl-1-octadecyl-3Hindol-1-ium (2) started from commercially available 2,3,3-Trimethylindolenine (1) and 1Iodooctadecane. For the synthesis of 5-((1,3-dioxoisoindolin-2-yl)methyl)-2,3,3-trimethyl-1octadecyl-3H-indol-1-ium (5), the 2,3,3-Trimethylindolenine (1) converted to 2-((2,3,3trimethyl-3H-indol-5-yl)methyl)isoindoline-1,3-dione (4) on reaction with (Hydroxymethyl)phthalimide (3), then on reaction with 1-Iodooctadecane. A compound dianil hydrochloride (8) was synthesized from $N$-formyl- $N$-methylaniline (7), 1methylcyclohexene, aniline and phosphoous oxychloride $\left(\mathrm{POCl}_{3}\right)$ in Dimethyl formamide (DMF). A compound 9 was synthesized by reacting of compound 2,3,3-trimethyl-1octadecyl-3H-indol-1-ium (2) with 5-((1,3-dioxoisoindolin-2-yl)methyl)-2,3,3-trimethyl-1octadecyl-3H-indol-1-ium (5) and dianil hydrochloride (8) in presence of acetic anhydride. The amine protecting group, phthalimide was removed by reacting with hydrazine to obtain compound DOCy7-methylamine (10) (Scheme S1).

DOCy7-PEG4-MTz (12) was synthesized by reaction with DOCy7-NH2 (10) and PEG4MTz-NHS (11) in basic condition (Scheme S2), DOCy7-PEG3400-MTz (16) was synthesized starting from VA-PEG3400- $\mathrm{NH}_{2}$ (13). VA-PEG3400- $\mathrm{NH}_{2}$ (13) was reacted with Methyl tetrazine NHS (14) in basic condition to obtain a VA-PEG3400-NHMTz (15), further which on coupling with DOCy7- $\mathrm{NH}_{2}$ (10) to obtain a DOCy7-PEG3400-MTz (16) (Scheme S3). Lipophilic indocarbocyanine dye DiI-methylamine (17) was made by using our previously reported synthesis. ${ }^{3}$ DiI-PEG3400-MTz (18) were synthesized by coupling reaction of DiI-NH2 (17) and VA-PEG3400-NHMTz (15) (Scheme S4).

\footnotetext{
1. König, S. G.; Krämer, R. (2017) Accessing Structurally Diverse Near-Infrared Cyanine Dyes for Folate Receptor-Targeted Cancer Cell Staining. Chem. Eur. J. (23), 9306-9312.

${ }^{2}$ Salon, J.; Wolińska, E.; Raszkiewicz, A.; Patonay, G.; Strekowski, L. (2005) Synthesis of Benz[e]indolium Heptamethine Cyanines Containing C-Substituents at the Central Portion of the Heptamethine Moiety. J. Heterocyclic Chem. (42) 959-961.

${ }^{3}$ Smith, W. J.; Tran, H.; Griffin, J. I.; Jones, J.; Vu, V. P.; Nilewski, L.; Gianneschi, N.; Simberg, D. (2018) Lipophilic indocarbocyanine conjugates for efficient incorporation of enzymes, antibodies and small molecules into biological membranes. Biomaterials (161) 57-68.
} 
The reaction between trans-cyclooctene (TCO) and tetrazine $(\mathrm{Tz})$ is known as Inverse Electron Demand Diels-Alder (IEDDA) click chemistry. ${ }^{4}$ The use of biorthogonal click chemistry in $\mathrm{mAb}$ as well as the small molecule has shown promising efficiency. ${ }^{5}$
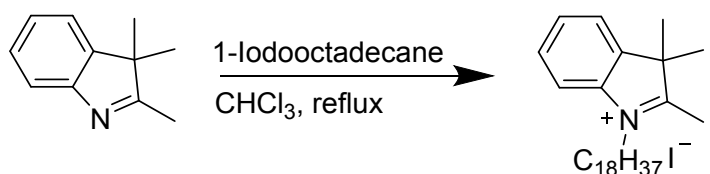

1

2 iodide

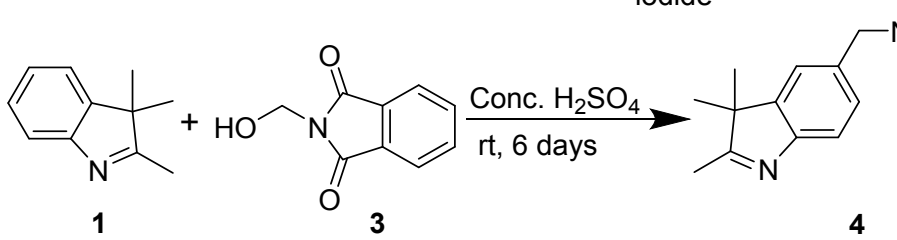<smiles>CC1=C[CH+]CCC1</smiles>

6 7

8 $\mathrm{HCl}$

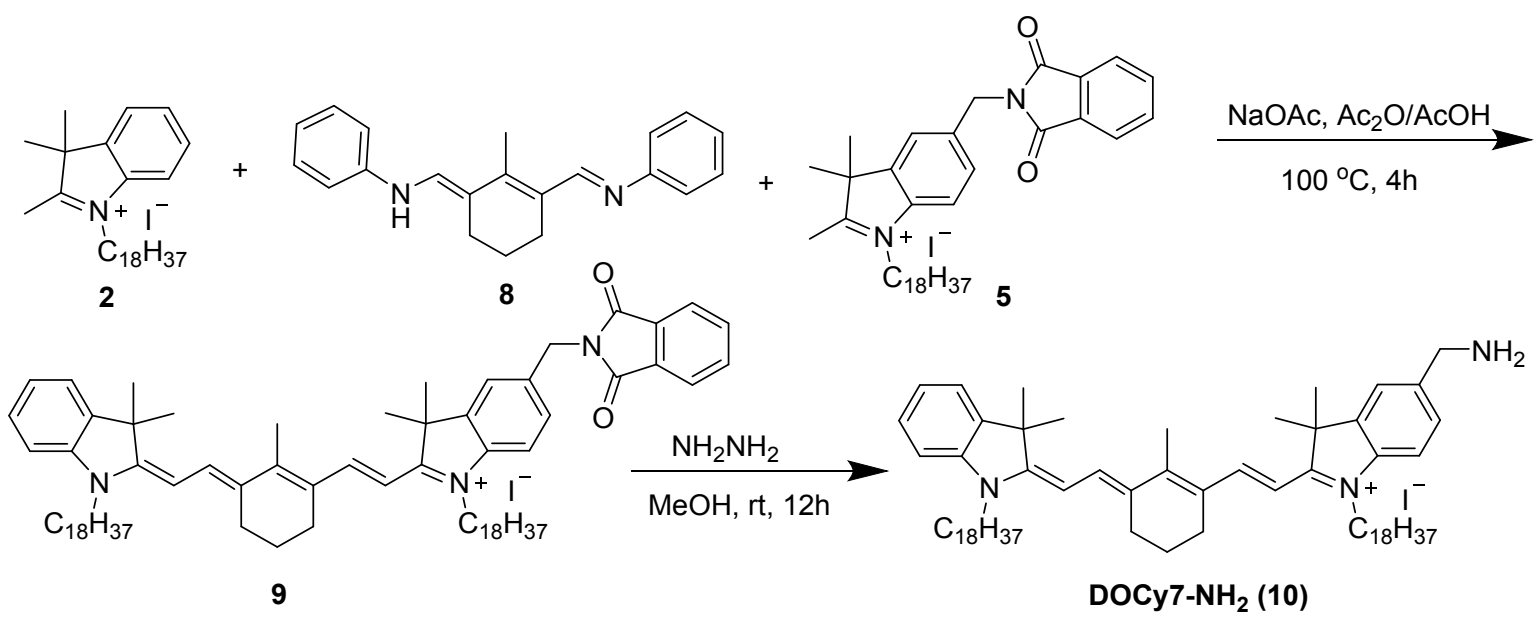

Scheme S1. Structures of DOCy7-methyl amine.

\footnotetext{
${ }^{4}$ Blackman, M. L.; Royzen, M.; Fox, J. M. Tetrazine Ligation: Fast Bioconjugation Based on Inverse-Electron-Demand Diels-Alder Reactivity J. Am. Chem. Soc. 2008, 130, 13518.

${ }^{5}$ Devaraj, N. K.; Upadhyay, R.; Hatin, J. B.; Hilderbrand, S. A.; Weissleder, R. Fast and Sensitive Pretargeted Labeling of Cancer Cells through a Tetrazine/trans-Cyclooctene Cycloaddition. Angew. Chem. Int. Ed. 2009, 48, 7013.
} 

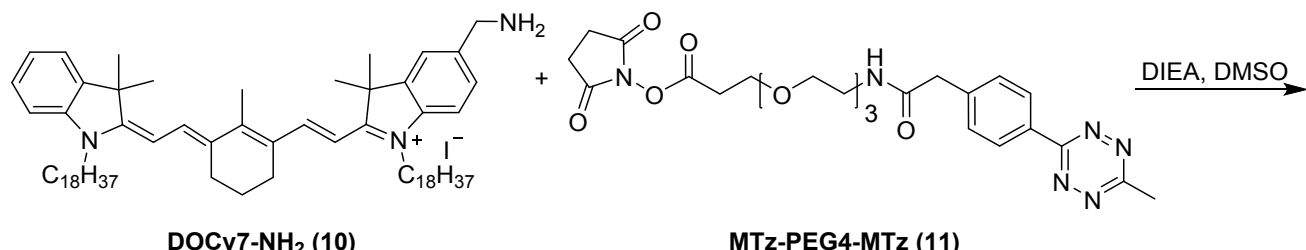

MTz-PEG4-MTz (11)

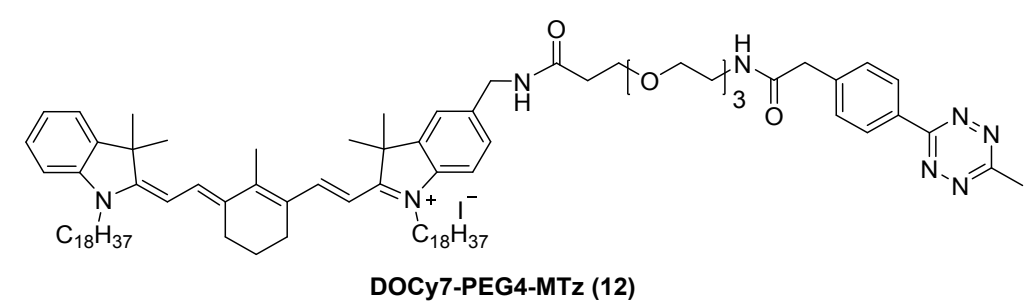

Scheme S2. Synthesis of DOCy7-PEG4-MTz (12).
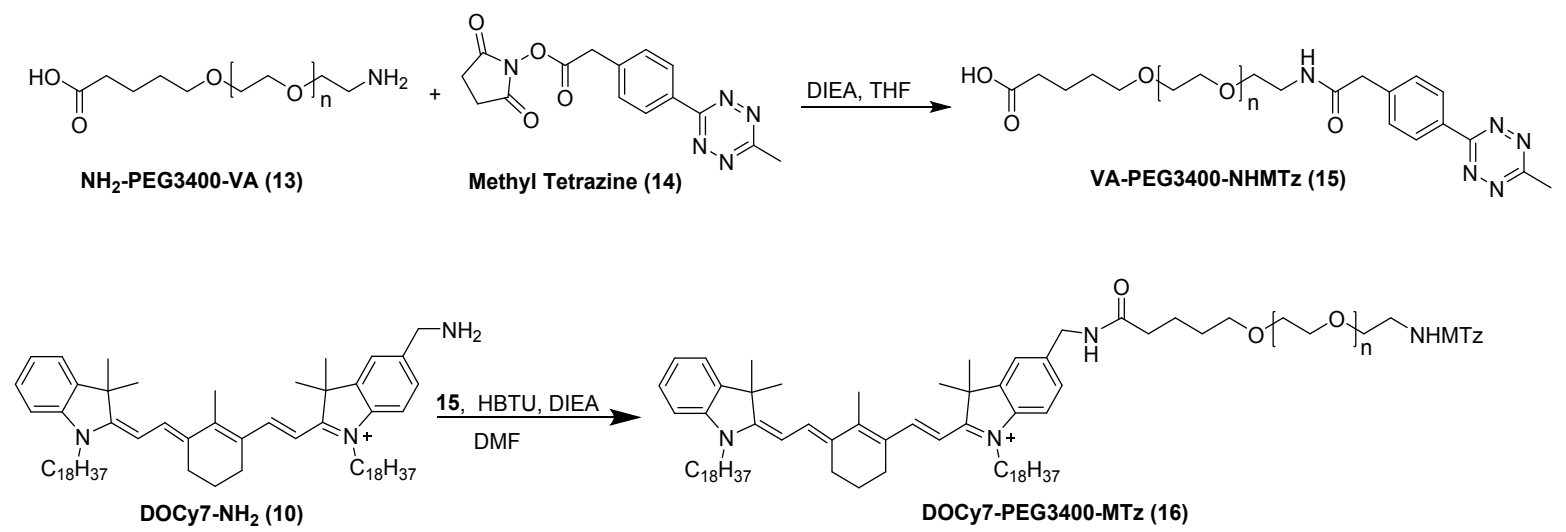

Scheme S3. Synthesis of DOCy7-PEG3400-MTz

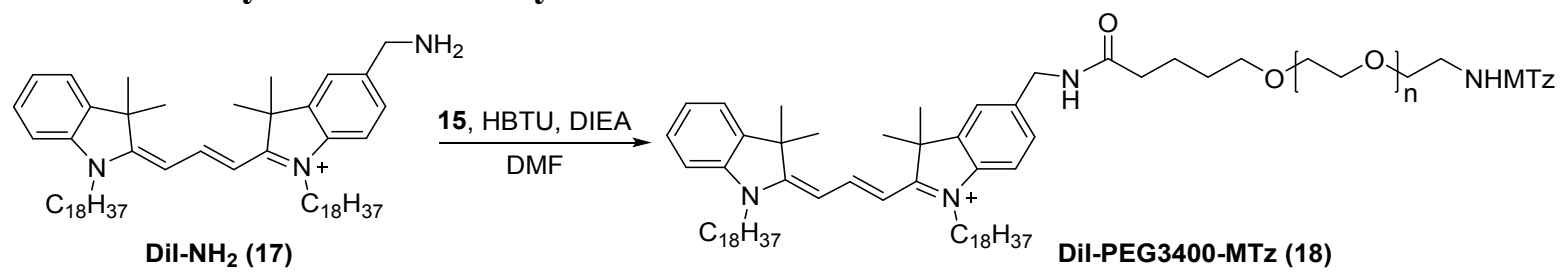

\section{Scheme S4. Synthesis DiI-PEG3400-MTz}

1.1 Synthesis of 2,3,3-trimethyl-1-octadecyl-3H-indol-1-ium (2): A stirred mixture of compound 2,3,3-Trimethylindolenine (1) (1.0 g $6.3 \mathrm{mmol}, 1$ eq.) and 1-Iodooctadecane (3.61 g, $9.5 \mathrm{mmol}, 1.5$ eq.) in chloroform $(5 \mathrm{~mL})$ were heated at reflux temperature for 96 hours. The solvent was then removed under reduced pressure and the resulting dark red residue was washed multiple times with hexanes and ether to give $2.1 \mathrm{~g}$ of indolium $\mathbf{2}$ as a dusty reddish brown solid. Yield 80.9\%, ${ }^{1} \mathrm{H}$ NMR (400 MHz, $\left.\mathrm{CDCl}_{3}\right) ; \delta 7.57$ (m, $\left.4 \mathrm{H}, \mathrm{Ar}-\mathrm{H}\right) ; 4.68$ (t, $J=$ $\left.7.8 \mathrm{~Hz}, 2 \mathrm{H}, \mathrm{CH}_{2}\right) ; 3.12$ (s, 3H, $\left.\mathrm{CH}_{3}\right) ; 1.87-1.97$ (m, $\left.2 \mathrm{H}, \mathrm{CH}_{2}\right) ; 1.67$ (s, $\left.6 \mathrm{H}, \mathrm{CH}_{3}\right) ; 1.42-1.51$ $\left(\mathrm{m}, 2 \mathrm{H}, \mathrm{CH}_{2}\right) ; 1.32-1.41\left(\mathrm{~m}, 2 \mathrm{H}, \mathrm{CH}_{2}\right) ; 1.19-1.32\left(\mathrm{~m}, 26 \mathrm{H}, \mathrm{CH}_{2}\right) ; 0.88(\mathrm{t}, J=6.8 \mathrm{~Hz}, 3 \mathrm{H}$, $\left.\mathrm{CH}_{3}\right)$. 
1.2 Synthesis of 2-((2,3,3-trimethyl-3H-indol-5-yl)methyl)isoindoline-1,3-dione (4): To a mixture of compound 2,3,3-Trimethylindolenine (1) $(2.0 \mathrm{~g}, 12.5 \mathrm{mmol}, 1.1$ eq.) and $\mathrm{N}$ (Hydroxymethyl)phthalimide (3) (2.02 g $11.4 \mathrm{mmol}, 1$ eq.) were added to $14.7 \mathrm{~mL}$ of concentrated sulfuric acid and stirred at room temperature for 6 days. The reaction was then poured over ice and made basic with concentrated aqueous ammonium hydroxide. After crystallizing at $-20{ }^{\circ} \mathrm{C}$ overnight, the resulting precipitate was filtered, rinsed with ice cold water, and dried under vacuum to give indolenine $\mathbf{4}$ as a light yellow shiny crystalline solid. Yield 88.3\%. ${ }^{1} \mathrm{H}$ NMR (400 MHz, $\mathrm{CDCl}_{3}$ ); $\delta$ 7.82-7.87 (m, 2H, Ar-H); 7.67-7.72 (m, 2H, Ar$\mathrm{H}) ;$ 7.44-7.48 (m, 1H, Ar-H); 7.35-7.42 (m, 2H, Ar-H); 4.87 (s, 2H, CH2); 2.25 (s, 3H, CH3) $1.28(\mathrm{~s}, 6 \mathrm{H}, \mathrm{CH} 3)$.

\subsection{Synthesis of 5-((1,3-dioxoisoindolin-2-yl)methyl)-2,3,3-trimethyl-1-octadecyl-3H-} indol-1-ium (5): A stirred mixture of compound 4 (1.0 g, $3.1 \mathrm{mmol}, 1$ eq.) and 1Iodooctadecane $(2.09 \mathrm{~g}, 5.5 \mathrm{mmol}, 1.75 \mathrm{eq}$.) in chloroform $(5 \mathrm{~mL})$ were heated at reflux temperature for 5 days. The solvent was then removed under reduced pressure and the residue was washed, filtered, and rinsed with hexanes and diethyl ether to give $\mathbf{5}$ as a dark red solid. Yield 83.6\%. ${ }^{1} \mathrm{H}$ NMR (400 MHz, $\mathrm{CDCl}_{3}$ ); $\delta$ 7.85-7.89 (m, 2H, Ar-H); 7.73-7.76 (m, 2H, Ar$\mathrm{H}) ; 7.69$ (d, $J=8.4 \mathrm{~Hz}, 1 \mathrm{H}, \mathrm{Ar}-\mathrm{H})$; 7.64-7.67 (m, 1H, Ar-H); 7.52 (d, $J=8.3 \mathrm{~Hz}, 1 \mathrm{H}, \mathrm{Ar}-\mathrm{H})$; $4.93\left(\mathrm{~s}, 2 \mathrm{H}, \mathrm{CH}_{2}\right) ; 4.64$ (t, J= $\left.7.7 \mathrm{~Hz}, 2 \mathrm{H}, \mathrm{CH}_{2}\right) ; 3.08\left(\mathrm{~s}, 3 \mathrm{H}, \mathrm{CH}_{3}\right) ; 1.81-1.93\left(\mathrm{~m}, 2 \mathrm{H}, \mathrm{CH}_{2}\right)$; $1.64\left(\mathrm{~s}, 6 \mathrm{H}, \mathrm{CH}_{3}\right) ; 1.38-1.48\left(\mathrm{~m}, 2 \mathrm{H}, \mathrm{CH}_{2}\right) ; 1.31-1.37\left(\mathrm{~m}, 2 \mathrm{H}, \mathrm{CH}_{2}\right) ; 1.21-1.29(\mathrm{~m}, 26 \mathrm{H}$, $\left.\mathrm{CH}_{2}\right) ; 0.87\left(\mathrm{t}, J=6.8 \mathrm{~Hz}, 3 \mathrm{H}, \mathrm{CH}_{3}\right)$

\subsection{Synthesis of $\quad \mathrm{N}-((\mathrm{E})-(2-\mathrm{methyl}-3-((E)-($ phenylimino)methyl)cyclohex-2-en-1-}

ylidene)methyl)aniline hydrogen chloride (8): A stirred solution of $N$-formyl- $N$ methylaniline (7) ( $2.11 \mathrm{~g}, 15.6 \mathrm{mmol})$ in chloroform $(2 \mathrm{~mL})$ at $-5{ }^{\circ} \mathrm{C}$ was treated with phosphorous oxychloride $(1.5 \mathrm{~mL}, 15.6 \mathrm{mmol})$, dropwise, and stirred for $1 \mathrm{~h}$ at $10{ }^{\circ} \mathrm{C}$. methylcyclohexene $(0.6 \mathrm{~mL}, 5.2 \mathrm{mmol})$ was added dropwise and the solution stirred at $45^{\circ} \mathrm{C}$ for $20 \mathrm{~h}$. The reaction mixture was poured into a beaker containing vigorously stirred water $(20 \mathrm{~mL})$. Solid potassium carbonate $(2 \mathrm{~g}, 14.5 \mathrm{mmol})$ was added carefully added. A solution of aniline hydrochloride salt $(1.52 \mathrm{~g}, 11.7 \mathrm{mmol})$ in water $(3 \mathrm{~mL})$ was added and the mixture stirred at ambient temperature for $30 \mathrm{~min}$. At this time, potassium carbonate ( $2 \mathrm{~g}, 14.5 \mathrm{mmol})$ was added portion wise and the resulting solution cooled to give a precipitate that was filtered, washed several times with cold water and stirred vigorously with acetone $(23 \mathrm{~mL})$ filtered and dried in vacuo to afford 8 dark red crystal. Yield $37 \% ; 1 \mathrm{H} \mathrm{NMR} \mathrm{(400} \mathrm{MHz,}$ DMSO-d $\left._{6}\right) \delta 10.57(\mathrm{bs}, 2 \mathrm{H}, \mathrm{NH}) ; 8.44(\mathrm{~s}, 2 \mathrm{H},=\mathrm{CH}) ; 7.59$ (d, J=7.8 Hz, 4H, Ar-H); 7.43 (t, 
$J=8.0 \mathrm{~Hz}, 4 \mathrm{H}, \mathrm{Ar}-\mathrm{H}) ; 7.22$ (t, $J=7.4 \mathrm{~Hz}, 2 \mathrm{H}, \mathrm{Ar}-\mathrm{H}) ; 2.56\left(\mathrm{~s}, 3 \mathrm{H}, \mathrm{CH}_{3}\right) ; 2.50-2.54$ (m, 4H, $\left.\mathrm{CH}_{2}\right) ; 1.75-1.84\left(\mathrm{~m}, 2 \mathrm{H}, \mathrm{CH}_{2}\right)$.

1.5 Synthesis of 2-((E)-2-((E)-3-(2-((E)-3,3-dimethyl-1-octadecylindolin-2ylidene)ethylidene)-2-methylcyclohex-1-en-1-yl)vinyl)-5-((1,3-dioxoisoindolin-2-yl)methyl)3,3-dimethyl-1-octadecyl-3H-indol-1-ium (9): A stirred mixture of compound 5 (200 mg, 0.35 mmol, 1 eq.), dianil hydrochloride (8) (142 mg, $0.42 \mathrm{mmol}, 1.1$ eq.), indolium (2) (144 $\mathrm{mg}, 0.35 \mathrm{mmol}, 1$ eq.), and sodium acetate $(95 \mathrm{mg}, 0.70 \mathrm{mmol}, 2$ eq.) were dissolved in a mixture of acetic acid $(5 \mathrm{~mL})$ and acetic anhydride $(5 \mathrm{~mL})$ under $\mathrm{N} 2$ was heated to $100{ }^{\circ} \mathrm{C}$ for $4 \mathrm{~h}$, cooled down to $25^{\circ} \mathrm{C}$, and agitated a heterogeneous mixture by addition of ethyl acetate $(20 \mathrm{~mL})$. The reaction was monitored by TLC using 10\% methanol in DCM as solvent. The reaction mixture was azeotroped with toluene and removed under reduced pressure, extracted with chloroform, washed with sat. $\mathrm{NaHCO}_{3}$ solution to give cyanine 9 as a dark green residue used as crude for the next step. MALDI-TOF (DHB matrix ) Calculated M/z $=1098.8749$, Found $\mathrm{M} / \mathrm{z}=1098.7701,1099.7740[\mathrm{M}+\mathrm{H}], 1100.7786[\mathrm{M}+2 \mathrm{H}]$.

1.6 Synthesis of 5-(aminomethyl)-2-((E)-2-((E)-3-(2-((E)-3,3-dimethyl-1octadecylindolin-2-ylidene)ethylidene)-2-methylcyclohex-1-en-1-yl)vinyl)-3,3-dimethyl-1octadecyl-3H-indol-1-ium, DOCy7- $\mathbf{N H}_{2}$ (10): Above crude cyanine compound 9 (100 mg, $0.091 \mathrm{mmol}, 1$ eq.) was dissolved in $5 \mathrm{~mL}$ of methanol, and then anhydrous hydrazine (271 ul, 8.65 mmol, 95 eq.) was added slowly. The reaction was stirred at room temperature for $48 \mathrm{~h}$ and monitored by TLC (10\% methanol in DCM). The solvent was then evaporated under reduced pressure and the resulting dark pink residue was purified by using prep HPLC and eluted with $90 \%$ to $95 \%$ methanol, to obtain $17 \mathrm{mg}$ of pure DOCy7- $\mathrm{NH}_{2}(\mathbf{1 0})$ as a dark green solid. Overall two step yield 17 \%. MALDI-TOF (DHB matrix) Calculated M/z=968.8694, Found $\mathrm{M} / \mathrm{z}=969.0248,970.0417[\mathrm{M}+\mathrm{H}], 971.0408$ [M+2H].

1.7 Synthesis of DOCy7-PEG4-MTz (12): A mixture of compound DOCy7- $\mathrm{NH}_{2}$ (10) (5 mg $0.0052 \mathrm{mmol}, 1$ eq.), MTz-PEG4-NHS (2.53 mg, $0.0077 \mathrm{mmol}, 1.5$ eq.) and DIEA (2.8 $\mu 1,0.015 \mathrm{mmol}, 3$ eq.) were stirred in DMSO at room temperature for 4 hours. The resulting reaction mixture was purified by using prep HPLC and eluted with $80 \%$ to $90 \%$ methanol, to obtain DOCy7-PEG4-MTz (12) as a dark green solid. Yield 65\%. MALDI-TOF (DHB matrix) Calculated $\mathrm{M} / \mathrm{z}=1387.0547$, Found $\mathrm{M} / \mathrm{z}=1388.922[\mathrm{M}+\mathrm{H}]$.

1.8 Synthesis of VA-PEG3400-NHMTz (15): A mixture of $\mathrm{NH}_{2}-\mathrm{PEG} 3400-\mathrm{VA}$ (13, 50 $\mathrm{mg}, 0.015 \mathrm{mmol}, 1$ eq.) Methyl tetrazine NHS (14, $7.21 \mathrm{mg} 0.022 \mathrm{mmol}, 1.5$ eq.) and DIEA ( $8 \mu 1,0.044$ mmol, 3 eq.) were stirred in THF at room temperature for 4 hours. The solvent was then evaporated under reduced pressure and the resulting dark pink residue was purified 
by using prep HPLC and eluted with $40 \%$ to $50 \%$ methanol/water, to obtain VA-PEG3400NHMTz (15) as a pink solid. Yield 68.3\%. ${ }^{1} \mathrm{H}$ NMR $\left(400 \mathrm{MHz}, \mathrm{CDCl}_{3}\right) ; \delta 9.98(\mathrm{bs}, 1 \mathrm{H}$, $\mathrm{NH}), 8.51$ (d, $J=8.3 \mathrm{~Hz}, 2 \mathrm{H}, \mathrm{Ar}-\mathrm{H}), 7.48$ (d, $J=8.3 \mathrm{~Hz}, 2 \mathrm{H}, \mathrm{Ar}-\mathrm{H}), 3.38-3.81$ (m, 330H, $\left.\mathrm{CH}_{2}\right)$ 3.05 (s, 3H, $\left.\mathrm{CH}_{3}\right), 2.31$ (t, $\left.J=7.2 \mathrm{~Hz}, 2 \mathrm{H}, \mathrm{CH}_{2}\right), 1.53-1.72\left(\mathrm{~m}, 4 \mathrm{H}, \mathrm{CH}_{2}\right)$.

1.9 Synthesis of DOCy7-PEG3400-MTz (16): A mixture of $\mathrm{DOCy}^{-\mathrm{NH}_{2}}$ (10) (5 mg, $0.0052 \mathrm{mmol}, 1$ eq.), VA-PEG3400-NHMTz (15, $17.5 \mathrm{mg}, 0.0052 \mathrm{mmol}, 1$ eq.), HBTU (3 mg, 0.0077 mmol, 1.5 eq.) and DIEA (2.8 $\mu 1,0.015$ mmol, 3 eq. $)$ were stirred in DMF at room temperature for $12 \mathrm{~h}$. The solvent was then evaporated under reduced pressure and the resulting dark green residue was purified by using prep HPLC and eluted with $50 \%$ to $60 \%$ methanol/water, to obtain DOCy7-PEG3400-MTz (16) as a dark green solid. Yield $53.4 \%{ }^{1} \mathrm{H}$ NMR (400 MHz, $\mathrm{CDCl}_{3}$ ); $\delta 8.58$ (d, J=8.3 Hz, 2H, Ar-H), 8.40-8.48 (bs, 1H, NH), 7.60-7.65 (m, 1H, Ar-H), 8.34 (d, J=8.3 Hz, 2H, Ar-H), 7.39-7.47 (m, 2H, Ar-H), 7.29-7.35 (m, 2H, Ar-H), 7.05-7.16 (m, 2H, Ar-H), 6.30-6.41 (m, 2H,CH), 4.53-4.60 (m, 2H, $\left.\mathrm{CH}_{2}\right), 4.01-4.13$ (m, 2H, $\left.\mathrm{CH}_{2}\right), 3.81-3.87\left(\mathrm{~m}, 2 \mathrm{H}, \mathrm{CH}_{2}\right), 3.78\left(\mathrm{~s}, 2 \mathrm{H}, \mathrm{CH}_{2}\right), 3.55-3.74\left(\mathrm{~m}, 270 \mathrm{H}, \mathrm{CH}_{2}\right), 3.45-$ $3.54\left(\mathrm{~m}, 6 \mathrm{H}, \mathrm{CH}_{2}\right), 3.12\left(\mathrm{~s}, 3 \mathrm{H}, \mathrm{CH}_{3}\right), 2.52-2.61\left(\mathrm{~m}, 2 \mathrm{H}, \mathrm{CH}_{2}\right), 1.79-1.92\left(\mathrm{~m}, 4 \mathrm{H}, \mathrm{CH}_{2}\right), 1.71-$ $1.78\left(\mathrm{~m}, 6 \mathrm{H}, \mathrm{CH}_{2}\right), 1.60-1.69\left(\mathrm{~m}, 2 \mathrm{H}, \mathrm{CH}_{2}\right), 1.18-1.53\left(\mathrm{~m}, 70 \mathrm{H}, \mathrm{CH}_{2}\right), 0.90(\mathrm{t}, J=6.8 \mathrm{~Hz}, 6 \mathrm{H}$, $\left.\mathrm{CH}_{3}\right)$.

1.10 Synthesis of DiI-PEG3400-MTz (18): A mixture of $\mathrm{DiI}_{-\mathrm{NH}_{2}}$ (10) (5 mg, 0.0058 mmol, 1 eq.), VA-PEG3400-NHMTz (15, 20.8 mg, 0.0058 mmol, 1 eq.), HBTU (3.3 mg, $0.0087 \mathrm{mmol}, 1.5$ eq.) and DIEA ( $3.2 \mu 1,0.017 \mathrm{mmol}, 3$ eq.) were stirred in DMF at room temperature for $12 \mathrm{~h}$. The solvent was then evaporated under reduced pressure and the resulting dark red-orange residue was purified by using prep HPLC and eluted with $70 \%$ to $80 \%$ methanol/water, to obtain Dil-PEG3400-MTz (18) as a dark red-orange solid. Yield. 83.5\%. ${ }^{1} \mathrm{H}$ NMR (400 MHz, $\mathrm{CDCl}_{3}$ ); $\delta 8.58$ (d, J=8.3 Hz, 2H, Ar-H), 7.70-7.75 (m, 2H, ArH), 7.70-7.75 (m, 2H, Ar-H), 7.56 (d, J=8.3 Hz, 2H, Ar-H), 7.33-7.46 (m, 2H, Ar-H), 7.16$7.20(\mathrm{~m}, 1 \mathrm{H}, \mathrm{Ar}-\mathrm{H}), 7.00-7.04(\mathrm{~m}, 1 \mathrm{H}, \mathrm{Ar}-\mathrm{H}), 6.78-6.83(\mathrm{~m}, 1 \mathrm{H}, \mathrm{CH}), 6.55-6.63(\mathrm{~m}, 1 \mathrm{H}$, $\mathrm{CH}), 4.37-4.71\left(\mathrm{~m}, 6 \mathrm{H}, \mathrm{CH}_{2}\right), 4.16-4.26\left(\mathrm{~m}, 2 \mathrm{H}, \mathrm{CH}_{2}\right), 3.79-3.87\left(\mathrm{~m}, 2 \mathrm{H}, \mathrm{CH}_{2}\right), 3.42-3.74(\mathrm{~m}$, $\left.190 \mathrm{H}, \mathrm{CH}_{2}\right), 3.12\left(\mathrm{~s}, 3 \mathrm{H}, \mathrm{CH}_{3}\right), 2.32-2.42\left(\mathrm{~m}, 2 \mathrm{H}, \mathrm{CH}_{2}\right), 1.56-1.88\left(\mathrm{~m}, 12 \mathrm{H}, \mathrm{CH}_{2}\right), 1.12-1.46$ $\left(\mathrm{m}, 60 \mathrm{H}, \mathrm{CH}_{2}\right), 0.90\left(\mathrm{t}, J=6.9 \mathrm{~Hz}, 6 \mathrm{H}, \mathrm{CH}_{3}\right)$. 
Final - Shots 500 - 1; Label C5

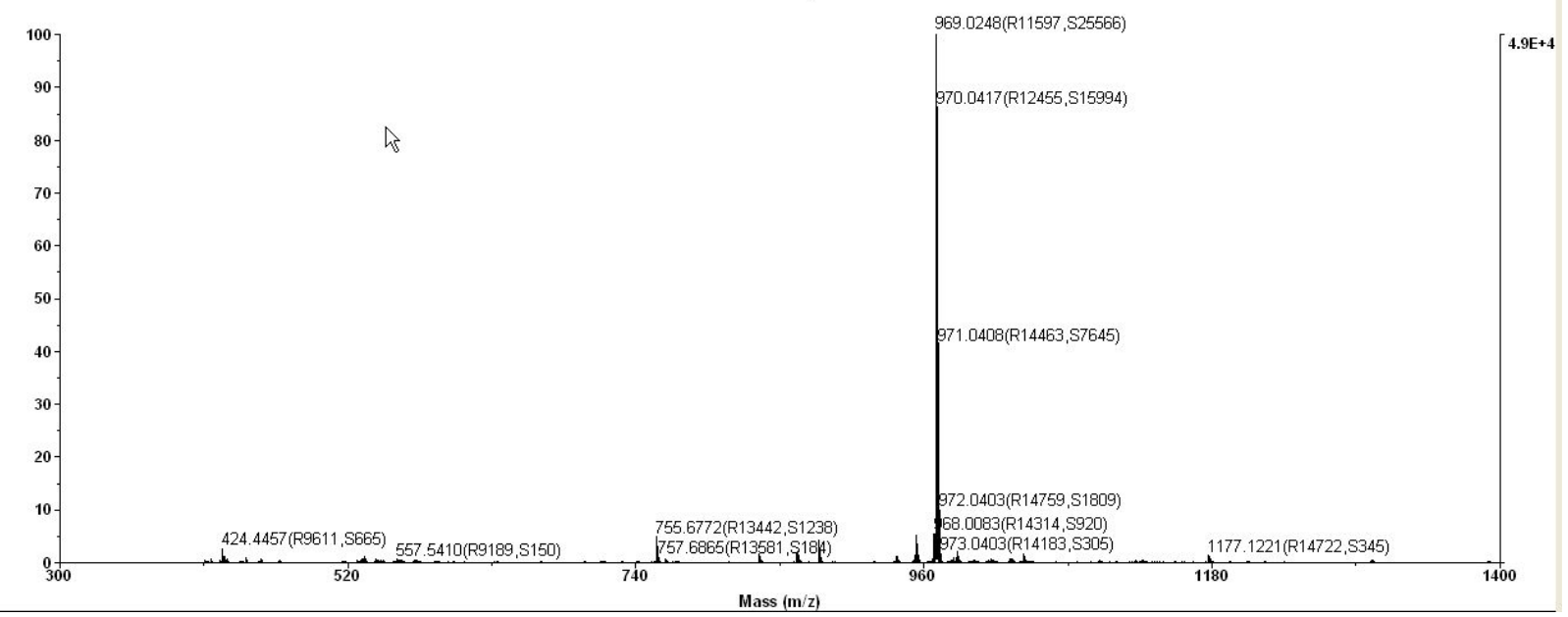

Mass spectrum of DOCy7- $\mathrm{NH}_{2}(10)$.

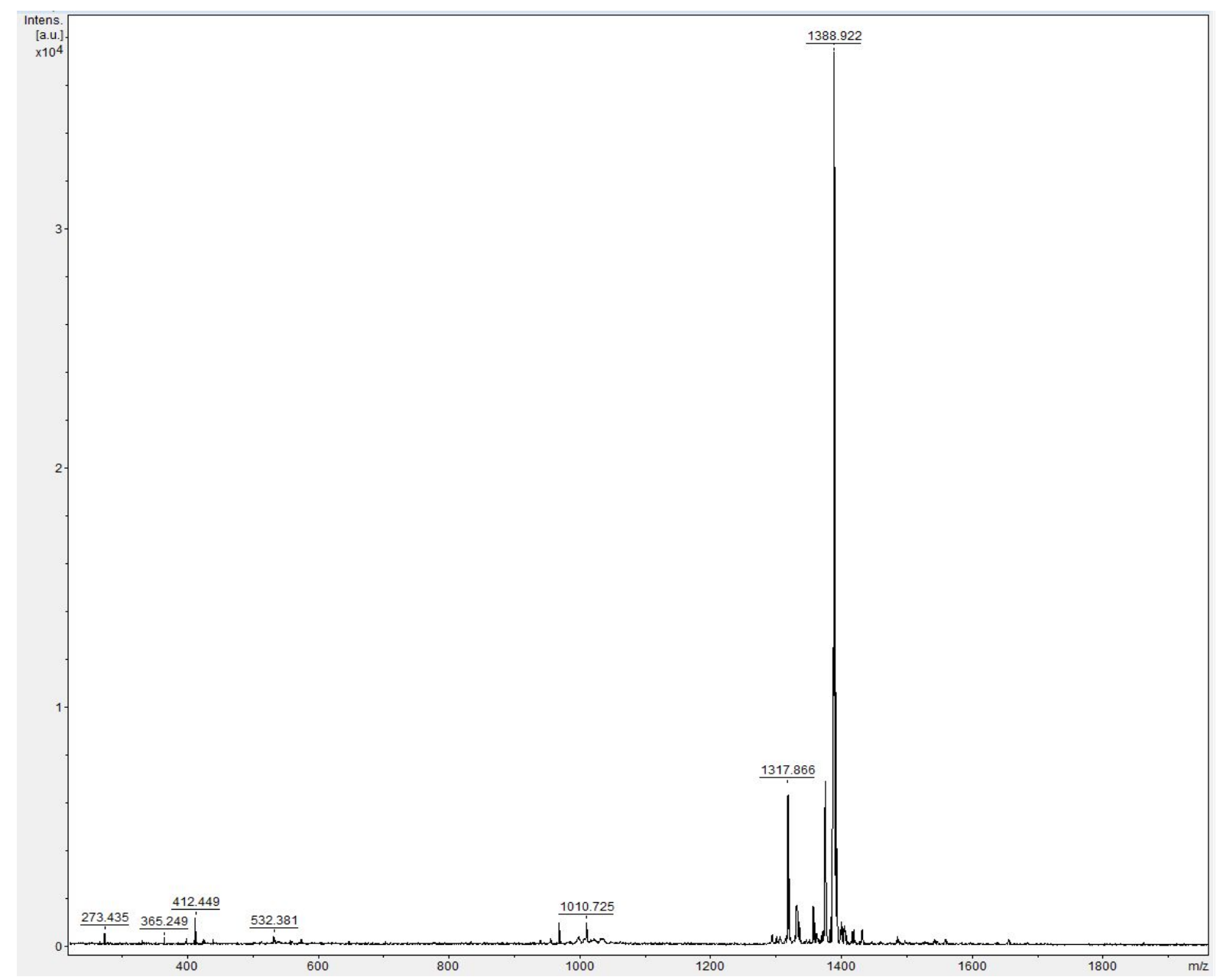

Mass spectrum of DOCy7-PEG4-MTz (12). 


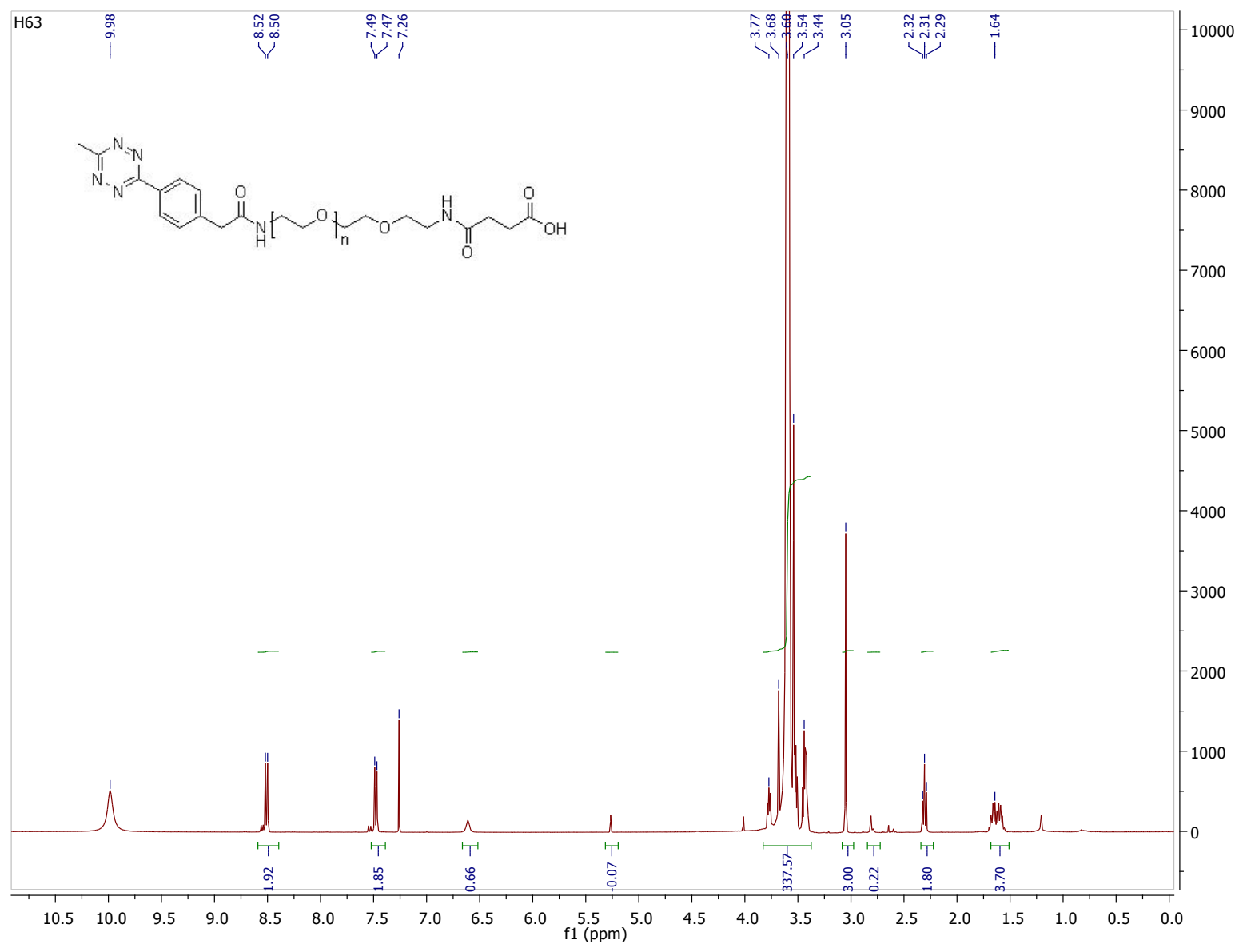

${ }^{1}$ H-NMR spectrum of VA-PEG3400-NHMTz (15). 


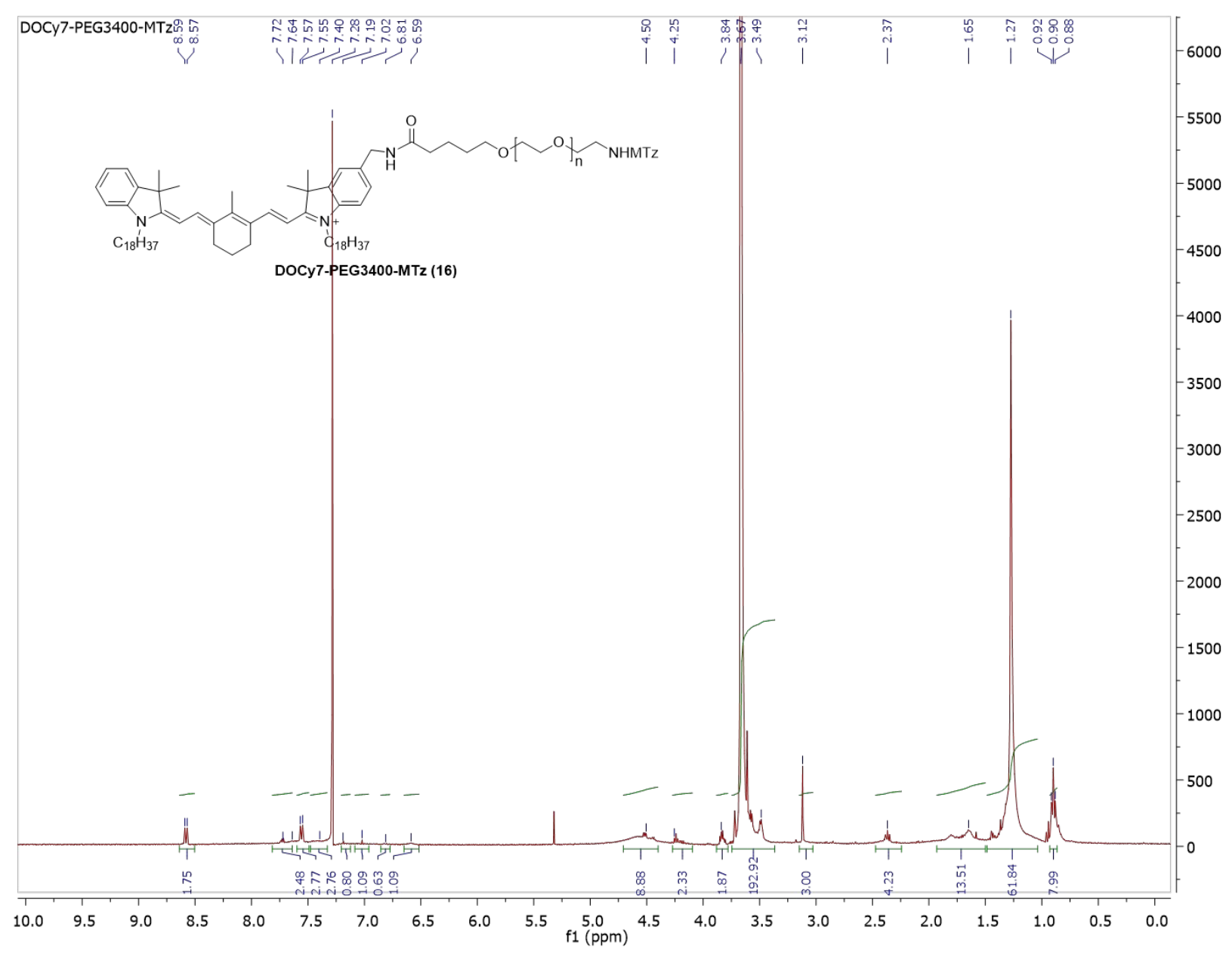

${ }^{1}$ H-NMR spectrum of DOCy7-PEG3400-MTz (16). 


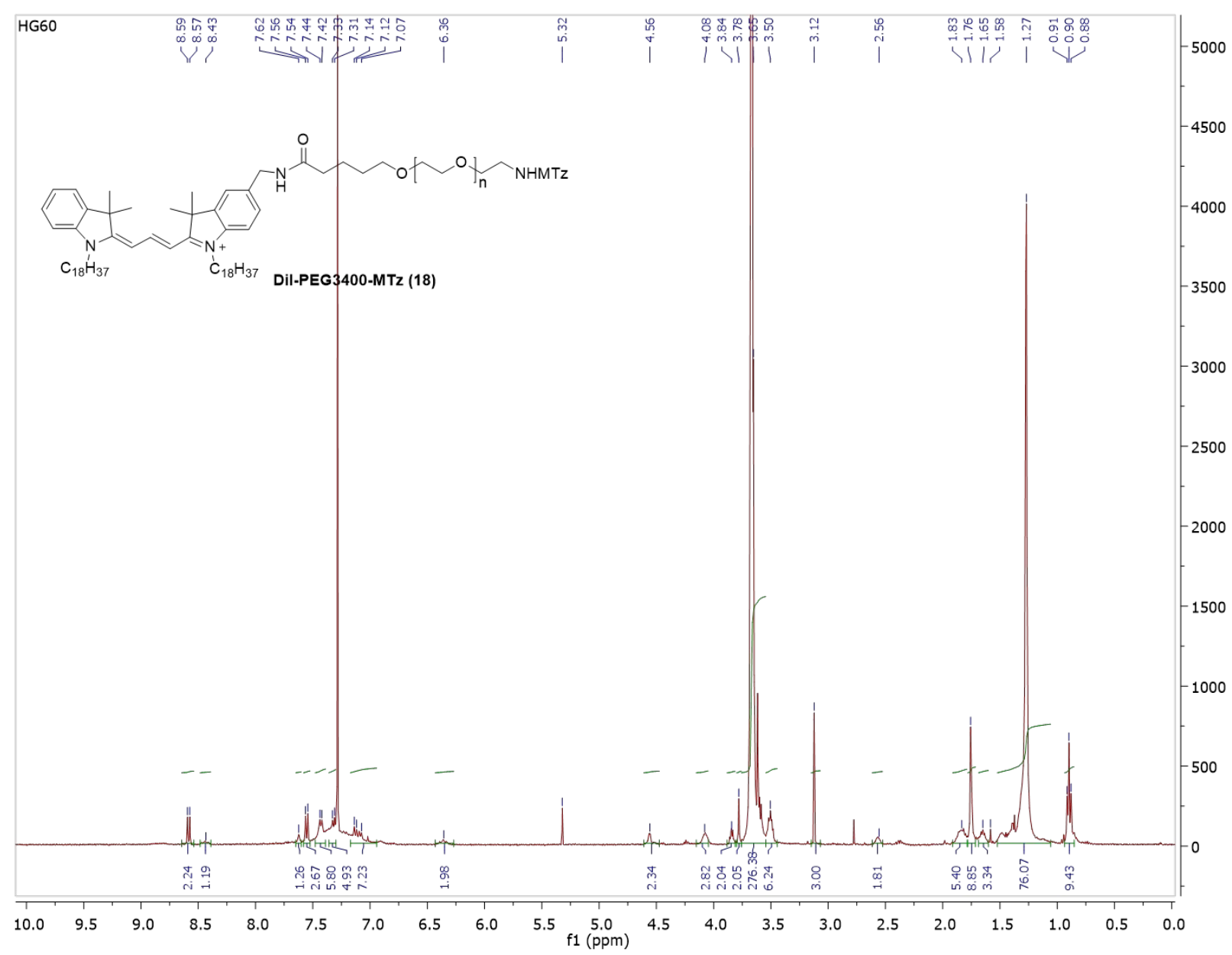

${ }^{1}$ H-NMR spectrum of DiI-PEG3400-MTz (18).

\section{Metabolomics}

Metabolomics analysis was performed on $20 \mu 1$ of painted RBCs at a dilution of 1:10 in lysis buffer (methanol:acetonitrile:water 5:3:2 v/v) prior to vortexing and centrifugation $(1,2)$. Supernatants were extracted at a dilution of 1:25 in lysis buffer (methanol:acetonitrile:water 5:3:2 $\mathrm{v} / \mathrm{v})$ as described $(1,2)$. All samples were analyzed via ultra-high pressure liquid chromatography coupled to mass spectrometry (UHPLC-MS). The analytical platform employs a Vanquish UHPLC system (Thermo Fisher Scientific, San Jose, CA, USA) coupled online to a Q Exactive mass spectrometer (Thermo Fisher Scientific, San Jose, CA, USA), as extensively described in prior work $(3,4)$. Metabolite assignments, isotopologue distributions, and correction for expected natural abundances of deuterium, ${ }^{13} \mathrm{C}$, and ${ }^{15} \mathrm{~N}$ isotopes were performed using MAVEN 722 (Princeton, NJ, USA). Statistical analysis was performed through median, fold-change comparisons and standard deviation (Microsoft 
Excel, Redmond, CA, USA; GraphPad Prism 8.1.0, Prism, San Diego, CA, USA). Principal component analysis was conducted in MetaboAnalyst 4.0.

\section{2) Supplemental Figures:}
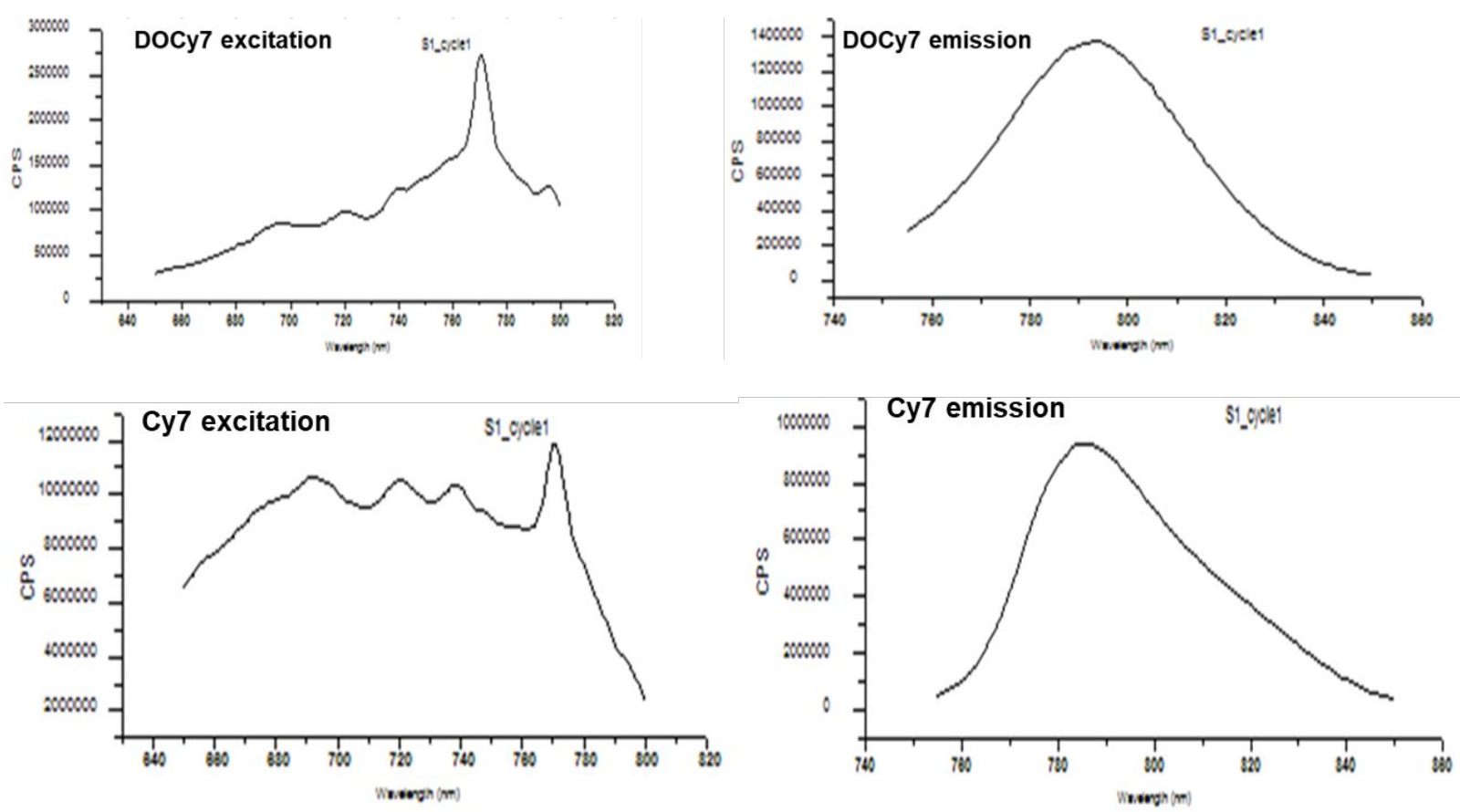

Supplemental Figure S1: DOCy7 excitation spectrum $(786 \mathrm{~nm})$ and DOCy7 emission spectrum (794 nm). Cy7 excitation spectrum (772 nm) and Cy7 emission spectrum $(790 \mathrm{~nm})$. 


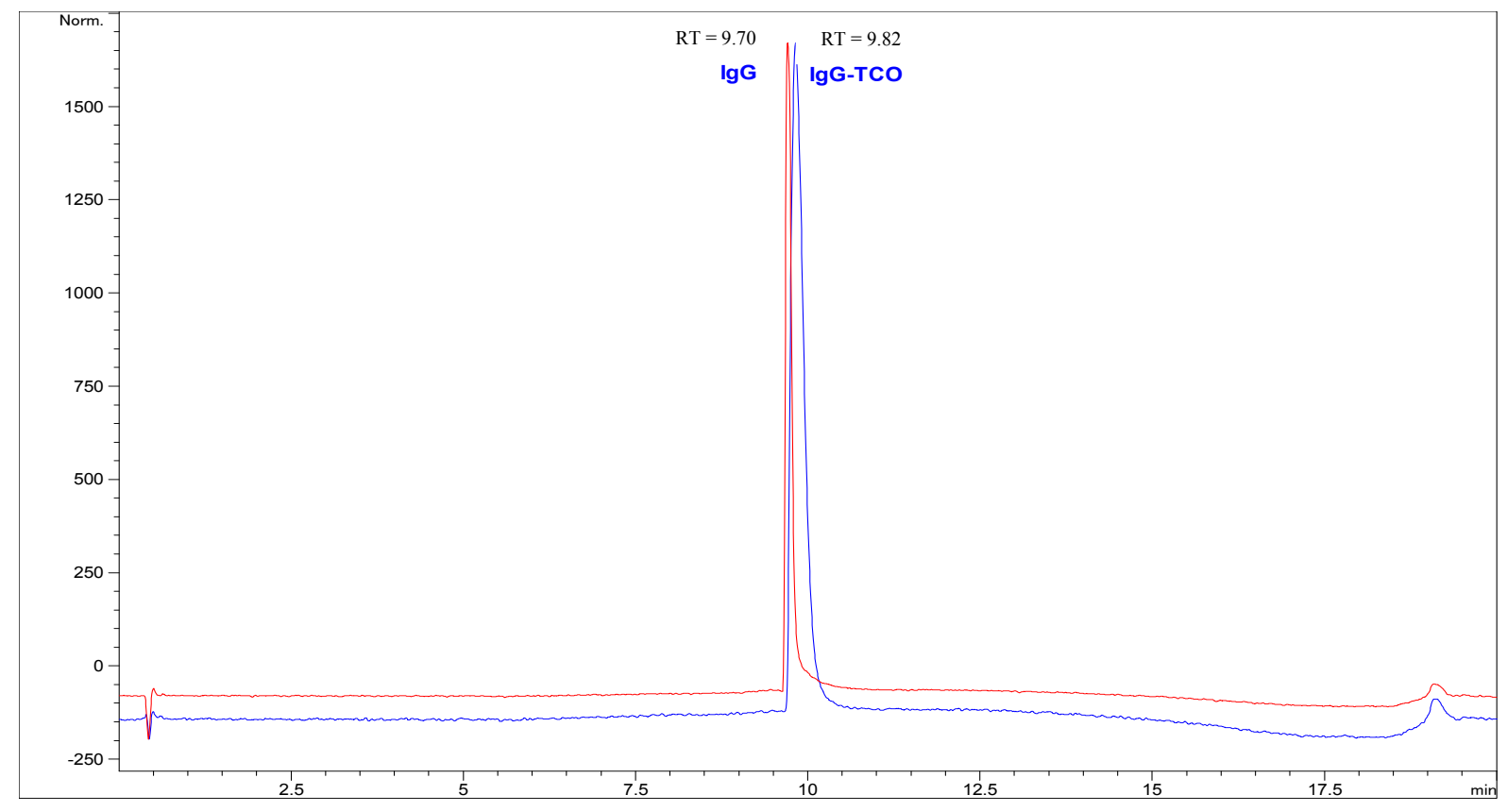

Supplemental Figure S2: HPLC spectrum of human IgG and human IgG labeled with TCO. 

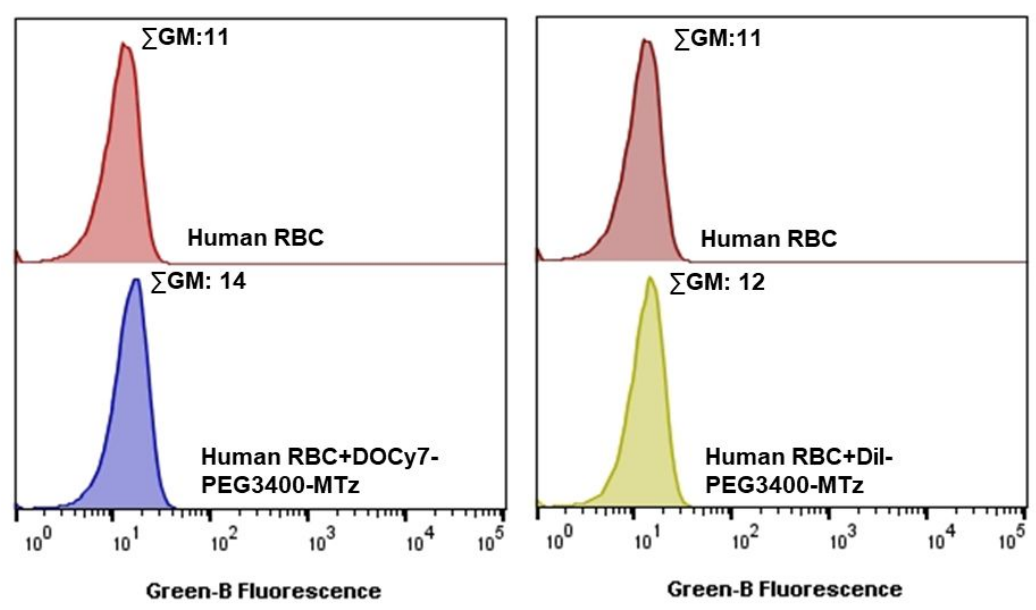

Supplemental Figure S3: Flow cytometry controls for Fig. 2-4. RBCs were painted with DOCy7-PEG3400-MTz or DiI-PEG3400-MTz. There was no effect on fluorescence in Green channel used to detect AlexaFluor 488-IgG. 


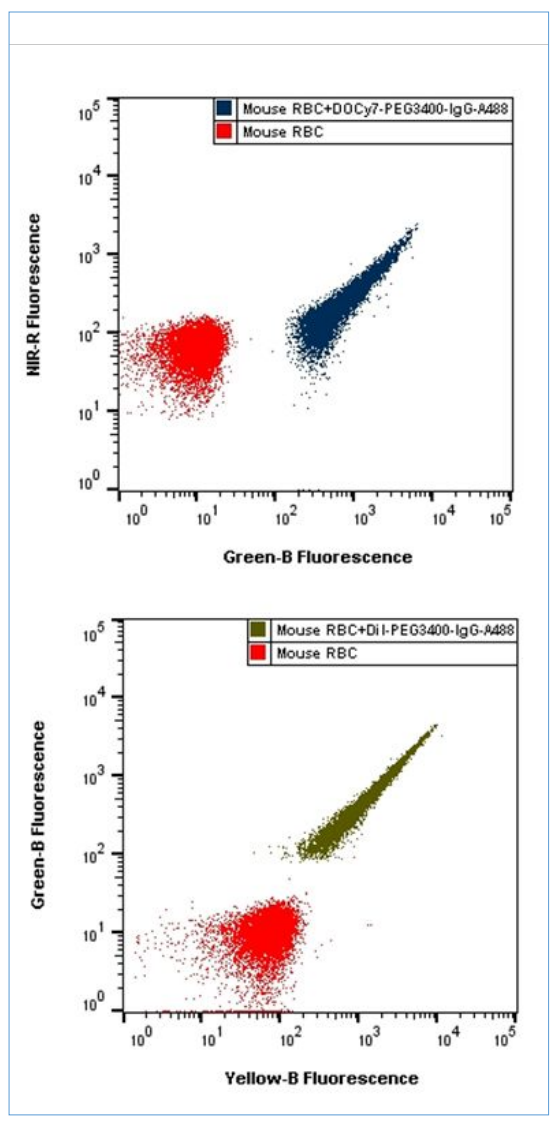

Supplemental Figure S4: Lipid painting of mouse RBCs. Top, RBCs were first painted with DOCy7-PEG3400-MTz and then conjugated with human IgG-TCO. IgG was detected with AlexaFluor 488 goat anti human IgG. Bottom, mouse RBCs were first painted with DiIPEG3400-MTz and then conjugated with human IgG-TCO. IgG was detected with AlexaFluor 488 goat anti human IgG. 
A.

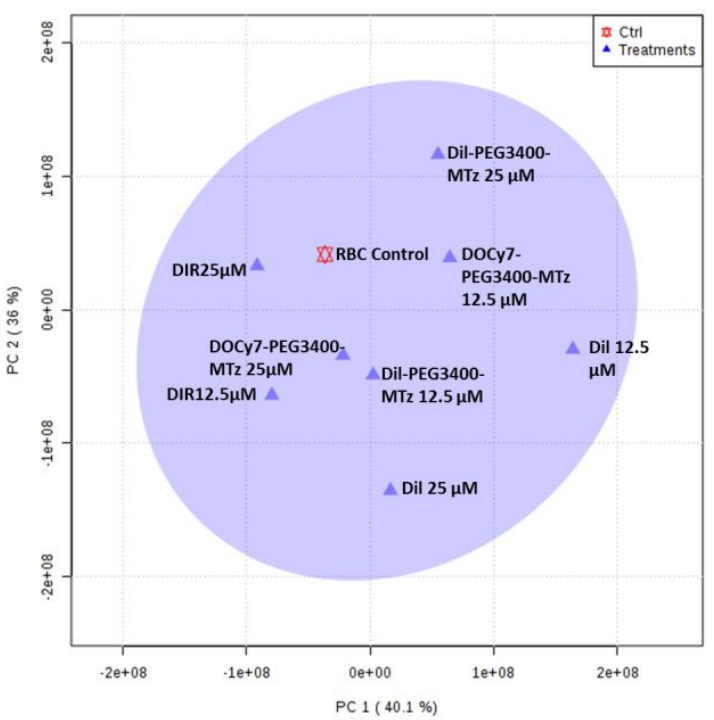

C.

Lactate

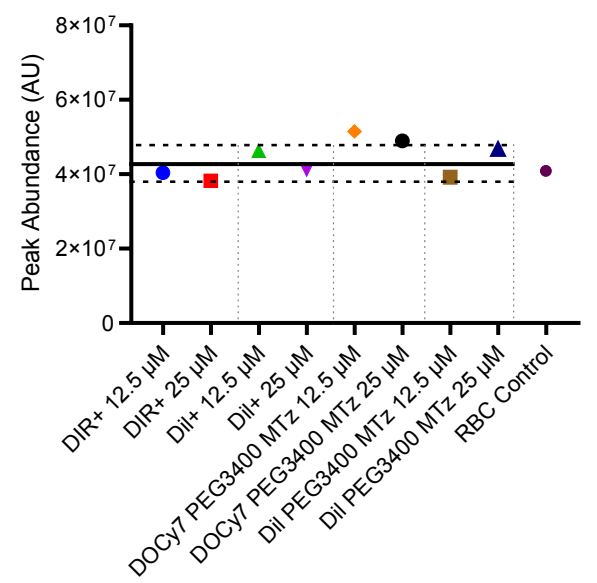

B.

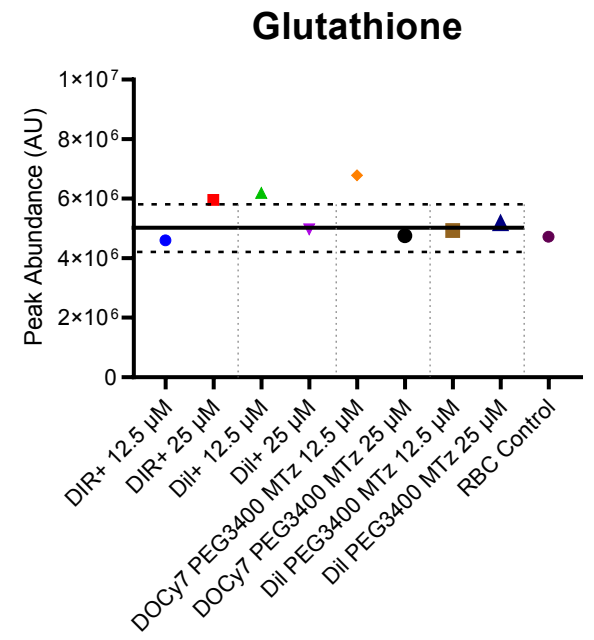

D.

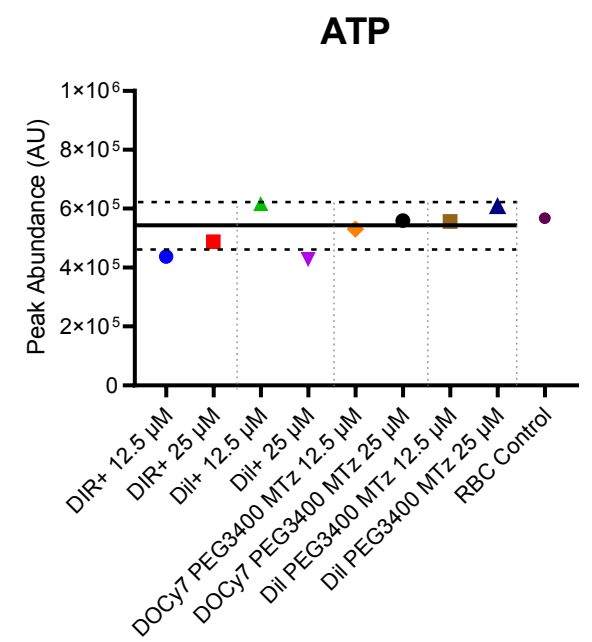

Supplemental Figure S5: Metabolomic profile of human RBCs painted with DiI, DiR or corresponding PEG3400-MTZ conjugates. (A) Score plot analysis reveals conjugates (green triangle) cluster around RBC control (red shape). Score plot was analyzed using MetaboAnalyst 4.0. Scatterplots (B) - (D) reveal metabolites of the glutathione homeostasis, glycolysis and purine pathways respectively. Except for $12.5 \mu \mathrm{M}$ DOCy7-PEG34000MTz, these metabolites show no significant variation between control and conjugates. Dark solid line represents median, while double broken lines represent one standard deviation from median. Scatter plots were analyzed using GraphPad Prism 8.1.0. 

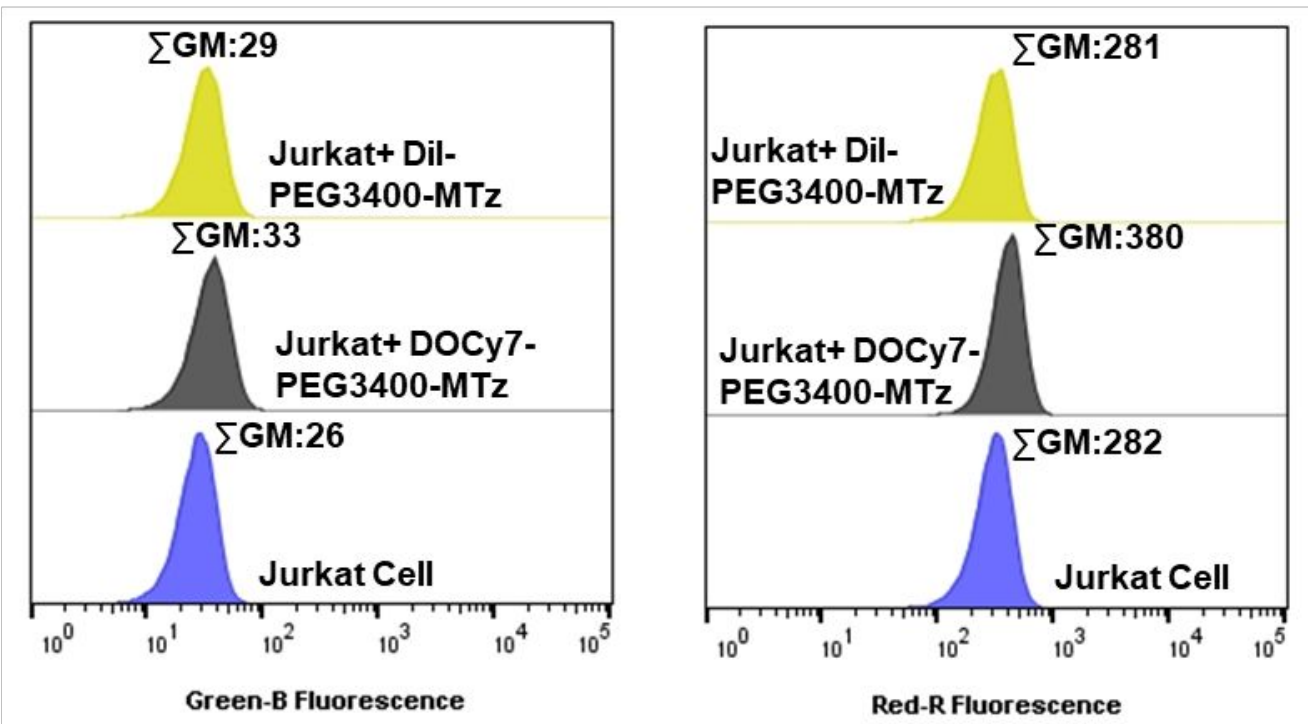

Supplemental Figure S6: Flow cytometry controls for Fig. 4-5. Cells were painted with DOCy7-PEG3400-MTz or DiI-PEG3400-MTz. There was no effect on the lipid fluorescence in the Green channel used to detect AlexaFluor 488-IgG, or in the Red channel used to detect Cy5-IgG.

\section{Additional Supplementary References}

(1) Culp-Hill, R., Srinivasan, A. J., Gehrke, S., Kamyszek, R., Ansari, A., Shah, N., Welsby, I., and D'Alessandro, A. (2018) Effects of red blood cell (RBC) transfusion on sickle cell disease recipient plasma and RBC metabolism. Transfusion 58, 27972806.

(2) D'Alessandro, A., Culp-Hill, R., Reisz, J. A., Anderson, M., Fu, X. Y., Nemkov, T., Gehrke, S., Zheng, C., Kanias, T., Guo, Y. L., Page, G., Gladwin, M. T., Kleinman, S., Lanteri, M., Stone, M., Busch, M., Zimring, J. C., Mast, A. E., Gottschall, J. L., Bialkowski, W., Anderson, L., Miller, J., Hall, A., Udee, Z., Johnson, V., Triulzi, D. J., Kiss, J. E., D'Andrea, P. A., Murphy, E. L., Guiltinan, A. M., Cable, R. G., Spencer, B. R., Johnson, S. T., Brambilla, D. J., Sullivan, M. T., Endres, S. M., Page, G. P., Guo, Y., Haywood, N., Ringer, D., Siege, B. C., Busch, M. P., Lanteri, M. C., Stone, M., Keating, S., Kanias, T., Gladwin, M., Kleinman, S. H., Glynn, S. A., Malkin, K. B., Cristman, A. M., and Donor, R. E. (2019) Heterogeneity of blood processing and storage additives in different centers impacts stored red blood cell metabolism as much as storage time: lessons from REDS-III-Omics. Transfusion 59, 89-100.

(3) Melamud, E., Vastag, L., and Rabinowitz, J. D. (2010) Metabolomic Analysis and Visualization Engine for LC-MS Data. Analytical Chemistry 82, 9818-9826.

(4) Nemkov, T., Hansen, K. C., and D'Alessandro, A. (2017) A three-minute method for high-throughput quantitative metabolomics and quantitative tracing experiments of central carbon and nitrogen pathways. Rapid Communications in Mass Spectrometry $31,663-673$. 